\title{
Reelin Stabilizes the Actin Cytoskeleton of Neuronal Processes by Inducing n-Cofilin Phosphorylation at Serine3
}

\author{
Xuejun Chai, ${ }^{1}$ Eckart Förster, ${ }^{1,3}$ Shanting Zhao, ${ }^{1}$ Hans H. Bock, ${ }^{2}$ and Michael Frotscher ${ }^{1,2}$ \\ ${ }^{1}$ Institut für Anatomie und Zellbiologie and 'Zentrum für Neurowissenschaften, Albert-Ludwigs-Universität Freiburg, D-79104 Freiburg, Germany, and \\ ${ }^{3}$ Institut für Anatomie I: Zelluläre Neurobiologie, Universität Hamburg, D-20246 Hamburg, Germany
}

The extracellular matrix protein Reelin, secreted by Cajal-Retzius cells in the marginal zone of the cortex, controls the radial migration of cortical neurons. Reelin signaling involves the lipoprotein receptors apolipoprotein E receptor 2 (ApoER2) and very low density lipoprotein receptor (VLDLR), the adapter protein Disabled1 (Dab1), and phosphatidylinositol-3-kinase (PI3K). Eventually, Reelin signaling acts on the cytoskeleton; however, these effects on cytoskeletal organization have remained elusive. In Reelin-deficient mutant mice, most cortical neurons are unable to migrate to their destinations, suggesting a role for Reelin signaling in the dynamic cytoskeletal reorganization that is required for neurons to migrate. Here, we show that Reelin signaling leads to serine 3 phosphorylation of $n$-cofilin, an actin-depolymerizing protein that promotes the disassembly of F-actin. Phosphorylation at serine3 renders n-cofilin unable to depolymerize F-actin, thereby stabilizing the cytoskeleton. We provide evidence for ApoER2, Dab1, Src family kinases (SFKs), and PI3K to be involved in $\mathrm{n}$-cofilin serine3 phosphorylation. Phosphorylation of $\mathrm{n}$-cofilin takes place in the leading processes of migrating neurons as they approach the Reelin-containing marginal zone. Immunostaining for phospho-cofilin in dissociated reeler neurons is significantly increased after incubation in Reelin-containing medium compared with control medium. In a stripe choice assay, neuronal processes are stable on Reelin-coated stripes but grow on control stripes by forming lamellipodia. These novel findings suggest that Reelin-induced stabilization of neuronal processes anchors them to the marginal zone which appears to be required for the directional migration process.

Key words: radial migration; Reelin signaling; cortical lamination; actin cytoskeleton; cofilin; reeler mutant

\section{Introduction}

The six-layered neocortex is formed by the sequential radial migration of neurons generated in the subventricular zone. Earlygenerated neurons form deep cortical layers, whereas lategenerated neurons are destined to superficial positions (Angevine and Sidman, 1961; Berry and Rogers, 1965). This characteristic inside-out layering implies that the late-generated neurons pass the early-generated ones and therefore migrate for longer distances. The sequential lamination of cortical neurons is controlled by the glycoprotein Reelin which is synthesized and secreted by Cajal-Retzius (CR) cells in the marginal zone (Rakic and Caviness, 1995; Curran and D'Arcangelo, 1998; Frotscher, 1998; Rice and Curran, 2001; Tissir and Goffinet, 2003; Soriano and Del Rio, 2005; Förster et al., 2006a,b; Cooper, 2008).

In the Reelin-deficient mutant reeler, cortical lamination is severely altered. Reeler-like phenotypes were found in mutants deficient in the two Reelin receptors, namely apolipoprotein $\mathrm{E}$ receptor 2 (ApoER2) and very low density lipoprotein receptor

\footnotetext{
Received June 25, 2008; revised 0ct. 8, 2008; accepted Nov. 25, 2008.

This work was supported by the Deutsche Forschungsgemeinschaft (SFB 780 and SFB 592 to M.F., F0 223/6-1 to E.F., and B0 1806/3-1 to H.H.B.). M.F. was supported by the Hertie Foundation. We thank Dr. Kaiyao Huang for helpful comments in the initial phase of the experiments, Dr. Sandra Dieni for helpful comments on this manuscript Bianka Brunne for help with the genotyping, Bozenna Meltzer, Ludmila Butenko-Golboyz, and Helga Herbort for technical assistance, and Dr. Udo Schumacher for his support with the real-time microscopy.

Correspondence should be addressed to Michael Frotscher, Institut für Anatomie und Zellbiologie, Albertstrasse 17, D-79104 Freiburg, Germany. E-mail: Michael.Frotscher@anat.uni-freiburg.de. DOl:10.1523/JNEUROSCI.2934-08.2009

Copyright $\odot 2009$ Society for Neuroscience $\quad$ 0270-6474/09/290288-12\$15.00/0
}

(VLDLR), and in Disabled1 (Dab1), a cytoplasmic adapter protein (Howell et al., 1997; Sheldon et al., 1997; Ware et al., 1997; Lambert de Rouvroit and Goffinet, 1998; Trommsdorff et al., 1999). Binding of Reelin to ApoER2 or VLDLR induces phosphorylation of Dab1 by nonreceptor tyrosine kinases (Hiesberger et al., 1999; Howell et al., 1999; Trommsdorff et al., 1999). Recently, divergent functions of ApoER2 and VLDLR in the migration of cortical neurons have been described (Hack et al., 2007). In apoer 2 mutants, but not $v l d l r$ mutants, late generated neurons are unable to pass early-generated cells and remain close to the subventricular zone, suggesting that Reelin signaling via ApoER2 influences the cytoskeleton to undergo dynamic changes during migration.

In migrating cells, the actin cytoskeleton (F-actin) at the leading edge is subjected to an organized process of assembly/disassembly to move the edge forward (Pollard and Borisy, 2003). These cytoskeletal changes are regulated by actin-binding proteins such as cofilin, an essential regulator of actin dynamics (Bamburg, 1999). Cofilin acts as an actin-depolymerizing protein that has severing activity; it binds to actin filaments (F-actin) and promotes their disassembly. Cofilin is located at the membrane of the leading edge of migrating cells, promotes lamellipodia formation by providing actin monomers (Jovceva et al., 2007; Kiuchi et al., 2007), and is required for directional migration (Dawe et al., 2003; Ghosh et al., 2004). In response to extracellular signals, cofilin is phosphorylated by LIM kinase 1 (LIMK1, Arber et al., 1998; Yang et al., 1998) which disables its capacity to bind and 
depolymerize F-actin. As a result, actin dynamics and subsequent process extension are inhibited (Moriyama et al., 1996; Nagaoka et al., 1996; Zebda et al., 2000). An essential role of cofilin in the migration of cortical neurons has recently been shown by Bellenchi et al. (2007) who found n-cofilin (nonmuscle cofilin) dysfunction to be associated with neuronal migration disorders.

In the present study we describe a role for Reelin signaling in $\mathrm{n}$-cofilin phosphorylation. Reelin signaling enhanced the activity of LIMK1, resulting in increased n-cofilin phosphorylation at serine 3 and thus a stabilization of the actin cytoskeleton.

\section{Materials and Methods}

Animals. Reeler mice (B6C3Fe-a/a-reln ${ }^{r l}$ ) were purchased from the Jackson Laboratory; dab1 ${ }^{-1-}$ mice (Howell et al., 1997) and apoer2 and vldlr knock-out mice (Trommsdorff et al., 1999) were obtained from Dr. J. Herz, Department of Molecular Genetics, UT Southwestern, Dallas, TX. All animals were maintained in accordance with the institutional guidelines of the University of Freiburg. Genotypes were confirmed by PCR analysis of genomic DNA.

Antibodies, inhibitors, and reagents. The following primary antibodies were used for immunocytochemical studies and Western blot analyses: mouse monoclonal anti-Reelin G10 (dilution 1:1000; Millipore), rabbit polyclonal anti-actin (1:1000, Sigma), mouse monoclonal anti-Map2 (1: 1000; Sigma), rabbit polyclonal anti-cofilin (1:200; Cell Signaling Technology), rabbit polyclonal anti-phospho-cofilin (ser 3; 1:1000, Santa Cruz Biotechnology), rabbit polyclonal anti-phospho-LIMK1 (1:1000; Cell Signaling Technology), rabbit polyclonal anti-AKT (1:1000; Cell Signaling Technology), rabbit polyclonal anti-phospho-AKT (ser 473; 1:1000; Cell Signaling Technology), rabbit polyclonal anti-phospho-Src (tyr 416; 1:1000; Cell Signaling Technology), rabbit monoclonal antibody to neuronal class III $\beta$-tubulin (TUJ1; 1:1000; Covance), mouse monoclonal anti-RC2 (1:5; Developmental Hybridoma Bank), mouse monoclonal anti-Nestin (1:1000; Millipore).

PP2 (4-amino-5-(4-chlorophenyl)-7-(t-butyl) pyrazolo ([3, 4-d]) pyrimidine), an inhibitor of SFKs, was purchased from Merck, and inhibitors of PI3K, LY294002 and Wortmannin, were purchased from Cell Signaling Technology.

Preparation of Reelin-containing supernatants and control supernatants. HEK 293-cells transfected with plasmid pcDNA3 combined with fulllength Reelin cDNA and stably expressing Reelin (D'Arcangelo et al., 1997; Förster et al., 2002), and control HEK 293-cells transfected with a plasmid encoding green fluorescent protein (GFP) were grown in DMEM (Dulbecco's modified eagle medium, low glucose, Invitrogen) with $10 \%$ fetal calf serum (FCS, Invitrogen), $1 \%$ penicillin-streptomycin (P/S, 10,000 U/ml, Invitrogen) and $0.9 \mathrm{~g} / \mathrm{L}$ G418 (Geneticin, Invitrogen) for $2 \mathrm{~d}$ to reach full confluence. The medium was then replaced by hybridoma serum-free medium (Invitrogen), and the cells were incubated for $3 \mathrm{~d}$ at $37^{\circ} \mathrm{C}$ in $5 \% \mathrm{CO}_{2}$. Conditioned medium of Reelin-synthesizing 293-cells and the control medium of GFP-expressing 293-cells were collected and centrifuged at a speed of $4000 \times g$ for 5 min to remove dead cells. The supernatants were used immediately for the acute treatment of neurons and hippocampal cell cultures. For the coating of coverslips, Reelin-enriched supernatants were concentrated tenfold with centricon 100 columns (Amicon, Millipore) before use.

Preparation of tissue from reeler mice, dab1 mutants and reelin receptor mutants, and treatment with recombinant Reelin. Reeler embryos $(n=$ 88), dab1 mutant embryos [ $n=20$, embryonic day (E) 17.5], apoer $2^{-/-}$ mutants $\left(n=7, \mathrm{E} 17.5\right.$ and E19) and vldlr ${ }^{-1-}$ mutants $(n=8, \mathrm{E} 17.5$ and E19), and wild-type littermates $(n=6)$ were harvested from pregnant, anesthetized dams (intraperitoneal injection of $10 \mathrm{ml} / \mathrm{kg}$ Avertin; Sigma). The tails of the embryos were removed for genotyping. The hemispheres were isolated in ice-cold HBSS (Invitrogen), and after removing the meninges, the tissue was chopped in the $x$ - and $y$-axis with a tissue chopper into $100-\mu \mathrm{m}$-thick small pieces. The pieces were collected and equally divided into two $1.5 \mathrm{ml}$ tubes and resuspended in ice-cold HBSS.

After centrifugation, the preparation buffer was discarded. $1 \mathrm{ml}$ of Reelin-containing supernatant or control supernatant was added to the cell pellets which were resuspended and incubated for $15 \mathrm{~min}$ at $37^{\circ} \mathrm{C}$. Thereafter, the tissue was centrifuged, supernatants were discarded, and the pellets were immediately frozen in liquid nitrogen and stored at $-80^{\circ} \mathrm{C}$ until use for protein extraction and Western blot analysis.

Treatment with recombinant Reelin and kinase inhibitors. Tissue from E17.5 reeler cerebral cortex was prepared as described. After centrifugation, neuronal pellets were suspended with $1 \mathrm{ml}$ of Reelin-containing supernatant or control supernatant supplemented with various inhibitors (see below), and incubated for $15 \mathrm{~min}$ at $37^{\circ} \mathrm{C}$. Inhibitors were diluted in dimethyl sulfoxide (DMSO, final concentration $0.5 \%$ ) and used at the following concentrations: PP2 $(10 \mu \mathrm{M})$, LY294002 $(20 \mu \mathrm{M})$, and Wortmannin (50 nM) (Bock et al., 2003; Konno et al., 2005). After treatment, the suspensions were centrifuged, and supernatants were removed. The pellets were immediately frozen in liquid nitrogen and stored at $-80^{\circ} \mathrm{C}$ until required for protein extraction and Western blot analysis. A total of 32 reeler mice (E17.5) were used for the experiments with PP2, 26 reeler mutants (E17.5) were used for the experiments with LY294002 and Wortmannin.

Preparation of protein extracts. Tissue pellets $\left(-80^{\circ} \mathrm{C}\right)$ were incubated in ice-cold hypertonic lysis buffer [pH 7.6, $50 \mathrm{~mm}$ Tris-HCl, $150 \mathrm{~mm}$ $\mathrm{NaCl}, 5$ mm EDTA-Na $\mathrm{N}_{2}, 1 \%$ (v/v) Nonidet P-40, 1\% Triton X-100, 0.5\% $(\mathrm{w} / \mathrm{v})$ SDS, $0.25 \%(\mathrm{w} / \mathrm{v})$ sodium deoxycholate] with $1 \%$ protease inhibitor (Sigma), and phosphatase inhibitor cocktails (Sigma). The tissue was lysed by repeated freezing in liquid nitrogen and thawing at $37^{\circ} \mathrm{C}(5$ times). After the tissue was triturated with a pipette tip to homogenize larger pieces of tissue and sonicated for $5 \mathrm{~min}$, the suspension was centrifuged at $20,000 \times g$ at $4^{\circ} \mathrm{C}$ for $30 \mathrm{~min}$. The resulting crude supernatants were taken, and protein concentration was measured by using BCA Protein Assay Kit (Pierce). Aliquots of the supernatants were immediately used for Western blotting or were stored at $-80^{\circ} \mathrm{C}$ until use.

Western blot analysis. Five to ten micrograms of each sample were diluted in ultrapure water containing $1 \times$ NuPAGE sample buffer (Invitrogen) and $1 \times \mathrm{NuPAGE}$ reducing agent (Invitrogen) to final volumes of $24 \mu \mathrm{l}$, boiled at $95^{\circ} \mathrm{C}$ for $5 \mathrm{~min}$, and then immediately placed on ice. The samples were separated by NuPAGE Bis-Tris, pH 7.0, 4-12\% PAGE (Invitrogen) with $1 \times$ NuPAGE MES-SDS running buffer (Invitrogen) and transferred electrophoretically to polyvinylidene fluoride (PVDF) membranes with $1 \times \mathrm{NuPAGE}$ transfer buffer (Invitrogen). For blotting, membranes were blocked with $5 \%(\mathrm{w} / \mathrm{v})$ nonfat milk or $5 \%$ bovine serum albumin (BSA) in Tris-buffered saline (TBS) at room temperature (RT) for $1 \mathrm{~h}$ and finally incubated with primary antibodies in blocking solution at $4^{\circ} \mathrm{C}$ overnight. This was followed by detection with an alkaline phosphatase-conjugated secondary antibody (Western Breeze Chemiluminescent Immunodetection Kit, Invitrogen). The immunoreaction was visualized by enhanced chemiluminiscence. At least three Western blots were analyzed for each experiment. Films were digitally scanned using an Artix Scan 1100 Scanner (Mikrotek), and band optical density (OD) was quantified by measuring the mean intensity of the band signal using Image J 1.40 analysis software (National Institutes of Health). Differences between groups were tested for statistical significance (mean \pm SEM, two-tailed Student's $t$ test, ${ }^{*} p<0.05,{ }^{* *} p<0.01,{ }^{* * *} p<0.001$ ).

Preparation of coverslips with patterned Reelin coating. Coverslips were coated with Reelin-containing stripes of $40 \mu \mathrm{m}$ width as described in detail by Knöll et al. (2007). In short, poly-ornithine-coated coverslips were placed on silicon stripe matrices, and concentrated Reelin supernatant was injected with a microliter syringe into the channels of the matrix and incubated for $30 \mathrm{~min}$. For visualization of the stripes, fluorescent microspheres $(0.5 \mu \mathrm{m}$ in diameter, Invitrogen) or fluorescent secondary antibodies were used as described (Knöll et al., 2007). The coated coverslips were then transferred to 24 -well plates and incubated in $10 \times$ concentrated supernatant from GFP-transfected control cells not containing Reelin to cover control stripes with the same protein mixture except Reelin. After washing with PBS, the coverslips were covered with incubation medium, and the stripe quality was checked under a fluorescence microscope.

Preparation of primary cell cultures of reeler and wild-type hippocampus and treatment with recombinant Reelin. For primary cell cultures, newborn (P0) reeler mutants and wild-type mice ( $n=10$ for each group), and for incubation on stripe matrices, rat pups (P5, $n=10)$ were used. 
The hippocampus was dissected and put into ice-cold HBSS. After removal of the meninges, the hippocampi of both hemispheres were collected and maintained in $15 \mathrm{ml}$ Falcon tubes (BD Biosciences) containing $3 \mathrm{ml}$ of $0.5 \%$ Trypsin and $0.53 \mathrm{~mm}$ EDTAx4 $\mathrm{Na}$ (Invitrogen) and incubated at $37^{\circ} \mathrm{C}$ for $10 \mathrm{~min}$. The hippocampi were then washed twice in ice-cold HBSS and manually triturated with a polished glass Pasteur pipet for several times. Then, the cells were centrifuged at low speed $(800 \times g)$ for 3 min to discard dead cells. The sediment was collected in fresh Falcon tubes and centrifuged again. The supernatant was discarded, and cell pellets were resuspended in $1 \mathrm{ml}$ of Neurobasal-A medium (Invitrogen), supplemented with 2\% B27 (Invitrogen), 1 mm Glutamax (Invitrogen), $100 \mathrm{U} / \mathrm{ml}$ penicillin and $100 \mu \mathrm{g} / \mathrm{ml}$ streptomycin (Invitrogen). Hippocampal cells were counted using a hemocytometer and suspended at a density of $5 \times 10^{5}$ cells in $0.5 \mathrm{ml}$ aliquots on glass coverslips inserted in 24-well plates. The coverslips had been coated overnight with a solution of $20 \mu \mathrm{g} / \mathrm{ml}$ poly-L-ornithine (Sigma) prepared in borate buffer, $\mathrm{pH}$ 8.1. After $2 \mathrm{~h}$ of incubation in a humidified incubator at $37^{\circ} \mathrm{C}$ and $5 \% \mathrm{CO}_{2}$ to allow for cell attachment, the medium was changed to remove dead cells. After another $24 \mathrm{~h}$ of incubation, cultures of wild-type cells were fixed with $4 \%$ paraformaldehyde (PFA) in $0.1 \mathrm{M}$ PBS, pH 7.4, for $15 \mathrm{~min}$ at RT and rinsed in $0.1 \mathrm{M}$ PBS for $1 \mathrm{~h}$ followed by incubation in blocking solution. In the reeler cultures, the medium was replaced on the first day in vitro (DIV1) by $500 \mu \mathrm{l}$ of Reelin-containing supernatant or control supernatant. After $15 \mathrm{~min}$ of incubation at $37^{\circ} \mathrm{C}$, the cultures were fixed with $4 \%$ PFA in $0.1 \mathrm{M}$ PBS for $15 \mathrm{~min}$ at RT and rinsed in $0.1 \mathrm{M}$ PBS for $1 \mathrm{~h}$ followed by incubation in blocking solution.

Immunostaining of cortical sections and primary cell cultures. For cortical tissue sections, reeler mutants and wild-type mice at E17.5, and for cell cultures newborn wild-type and reeler mice were used ( $n=6$ for each group). Pregnant dams were anesthetized with isoflurane (Abbott), and the embryos were dissected in ice-cold HBSS. P0 mice were decapitated under hypothermic anesthesia. Brains were removed and immersion-fixed in $0.1 \mathrm{M}$ PBS containing $4 \%$ PFA overnight at $4^{\circ} \mathrm{C}$. After washing for $2 \mathrm{~h}$ at RT in $0.1 \mathrm{M}$ PBS, brains were embedded in $5 \%$ agar and cut into $40-\mu \mathrm{m}$-thick slices on a Leica VT 1000 S vibratome (Leica Microsystems). The sections were placed in a 24-well plate containing $0.1 \mathrm{M}$ PBS.

Tissue sections and cell cultures were preincubated with blocking solution (5\% normal goat serum and 1\% BSA in $0.1 \mathrm{~m} \mathrm{PBS}$ containing $0.2 \%$ Triton X-100) at RT for $1 \mathrm{~h}$ and then incubated with the following primary antibodies diluted in blocking solution overnight at $4^{\circ} \mathrm{C}$ : mouse anti-Reelin (G10), rabbit anti-phospho-cofilin, rabbit anti-Map2, mouse anti-RC2, and mouse anti-Nestin. After washing in $0.1 \mathrm{M}$ PBS for $1 \mathrm{~h}$, sections or cultured cells were incubated in secondary antibodies diluted in $0.1 \mathrm{M}$ PBS for $1 \mathrm{~h}$ at RT. The secondary antibodies were Alexa Fluor 488-conjugated goat anti-rabbit (green, 1:300; Invitrogen) and/or Alexa Fluor 568-conjugated goat anti-mouse IgG (red, 1:300; Invitrogen) Alexa Fluor 555-conjugated goat anti-mouse (red, 1:300; Invitrogen). Sections or cultured cells were counterstained with DAPI (1:10,000; Invitrogen). Some cell cultures were stained for F-actin with $10 \mu \mathrm{M}$ TRITC-labeled phalloidin (Sigma). After rinsing in $0.1 \mathrm{M}$ PBS for $2 \mathrm{~h}$, sections and cells $\left.{ }^{* * *} p<0.001\right)$.
B

cofilin phosphorylation
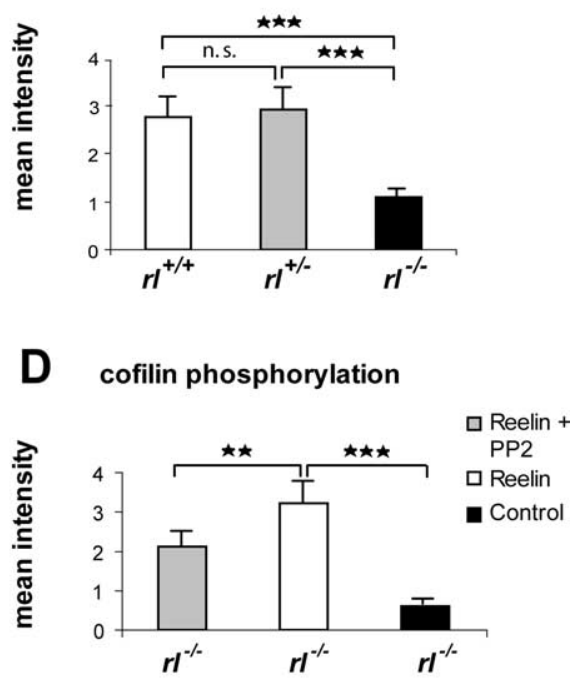

E LIMK1 phosphorylation

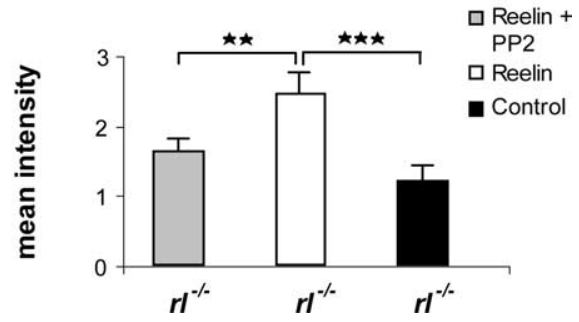

Reelin +

Reelin

Control

Figure 1. Reelin induces phosphorylation of $\mathrm{n}$-cofilin. $\boldsymbol{A}$, In cortical lysates prepared from E18 wild-type animals $\left.(r)^{+/+}\right)$or heterozygous mice $\left(r l^{+/-}\right)$, the protein level of phosphorylated $n$-cofilin at serine3 (p-cofilin) is higher than that of their reeler $\left(\mathrm{rl}^{-/-}\right)$littermates. No difference was found when lysates from heterozygous mice and from wild-type animals were compared. experiments). Signals are expressed as mean \pm SEM. Cofilin phosphorylation is significantly decreased in reeler tissue when with tissue from wild-type animals or heterozygous mice ( ${ }^{* * *} p<0.001$, Student's test; $n . S .$, not significant). C, Reelin n-cofilin-phosphorylating kinase, was similarly increased after Reelin treatment. Phosphorylation levels of both n-cofilin and protein loading. $\boldsymbol{D}, \boldsymbol{E}$, Densitometric analysis of cofilin and LIMK1 phosphorylation in tissue treated with Reelin or Reelin + PP2 Results are from five independent experiments; statistically significant differences are indicated (unpaired $t$ test, ${ }^{* *} p<0.01$,

were mounted in Moviol on glass slides. Sections and cultured cells were photographed using an Olympus microscope (Olympus BX61) or a confocal microscope (LSM 510, Carl Zeiss) and a $40 \times$ oil-immersion objective. The confocal microscope was used to acquire $z$-series of brain sections at $1 \mu \mathrm{m}$ intervals through a tissue depth of $21 \mu \mathrm{m}$. The $z$-series were then visualized as single optical scans with concurrent orthogonal views using LSM 510 software.

Real-time microscopy. After initial incubation at $37^{\circ} \mathrm{C}$ in a humidified $5 \% \mathrm{CO}_{2}$ atmosphere, dissociated neurons on stripe assays were transferred to a live incubation chamber $\left(37^{\circ} \mathrm{C}\right.$, humidified, $\left.5 \% \mathrm{CO}_{2}\right)$, attached to an inverted Axiovert 200 microscope (Carl Zeiss). Images at single time points were captured with an AxioCam MRm camera (Carl Zeiss) and processed with Axiovision LE software.

Quantitative immunofluorescence measurements. The phosphorylation of cofilin at serine 3 in reeler hippocampal cells (DIV 1) treated with recombinant Reelin or with control supernatant for $15 \mathrm{~min}(n=100$ cells each in a total of 48 cultures) was measured by using analysis SIS software (Soft Imaging Systems). In brief, 15- $\mu \mathrm{m}$-long phospho-cofilin-positive 
A

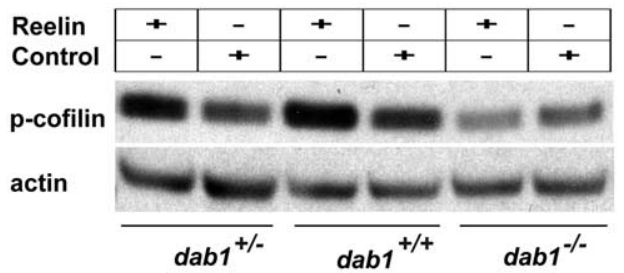

C

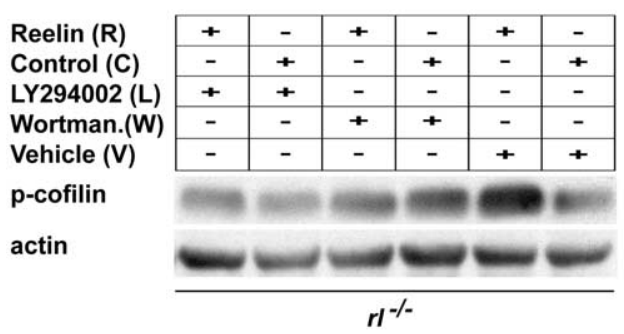

E

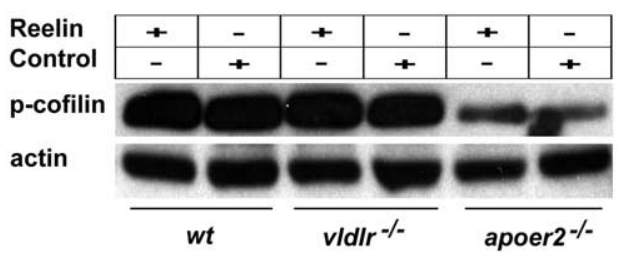

B

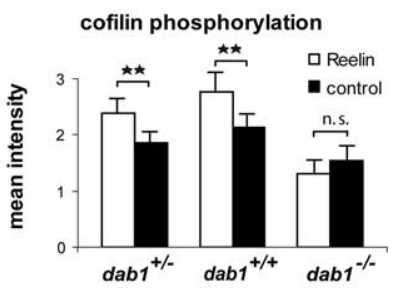

D

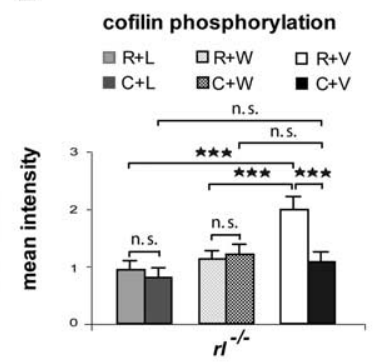

$\mathbf{F}$

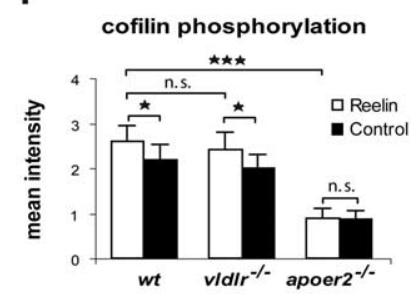

G

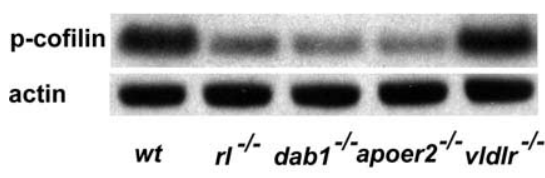

H

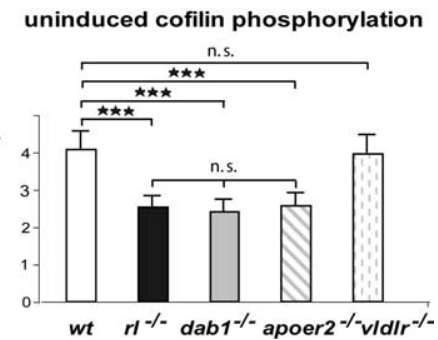

Figure 2. Reelin-induced phosphorylation of n-cofilin involves Dab1, PI3K, and ApoER2. A, Reelin upregulates p-cofilin in E17.5 $\mathrm{dab}^{+/-}$mice and $d a b 1^{+/+}$mice compared with untreated control tissue, an effect that was abolished in dab1 $1^{-1-}$ mutants. Actin was used as loading control. $\boldsymbol{B}$, Densitometric analysis of Reelin-treated tissue from E17.5 $\mathrm{dab}^{-1}{ }^{-}$mice, heterozygous mice, and wild-type animals. Statistically significant differences are indicated $\left({ }^{* *} p<0.01\right.$; n.s., not significant). $\boldsymbol{C}$, Blocking PI3K by LY294002 and Wortmannin, respectively, reduced Reelin-induced p-cofilin in E17.5 reeler cortical tissue when compared with unblocked, Reelin-treated samples. Actin was used to control for protein loading. $\boldsymbol{D}$, Densitometric analysis of the effects of PI3K inhibitors ( 3 independent experiments). Statistically significant differences are indicated $\left({ }^{* * *} p<0.001\right.$; n.s., not significant). $\boldsymbol{E}$, There was no difference in the level of Reelin-induced $n$-cofilin phosphorylation when E19 wild-type animals and $v^{\prime d d r}{ }^{-1}$ mice were compared. However, $n$-cofilin phosphorylation was strongly reduced in tissue of apoer ${ }^{-1}{ }^{-}$mutants. Actin Western blot as a loading control. $F$, Densitometric analysis of cofilin phosphorylation in Reelin-treated tissues and control tissues from wild-type mice, vldlr ${ }^{-\prime-}$ mice, and apoer ${ }^{-\prime-}$ mice. Significant differences are indicated $\left({ }^{*} p<0.05,{ }^{* * *} p<0.001 ; \mathrm{n}\right.$. S., not significant). $\mathbf{G}, \boldsymbol{H}$, Levels of uninduced p-cofilin (not induced by incubating the tissue in the presence of Reelin) in wild-type

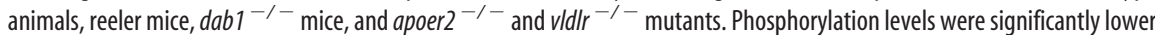
in reeler mice, dab1 $1^{-1-}$ mice, and apoer $2^{-/-}$mice when compared with wild-type animals ( $\left.{ }^{* * *} p<0.001\right)$. No significant differences were found between tissues from reeler mice, $\mathrm{dab} 1^{-1-}$ mice, and apoer ${ }^{-1-}$ mice.

neuronal processes $5 \mu \mathrm{m}$ away from their origin from the cell body were traced, subdivided into proximo-distal segments, and then fluorescence intensities were measured. The ratio of fluorescence intensity of p-cofilin pixels to phalloidin or Map2 pixels was taken for each image and used for comparison between experimental conditions. Differences between groups were tested for statistical significance using the two-tailed Student's $t$ test $(p<0.01)$.

Substrate-dependent $\mathrm{p}$-cofilin immunostaining in the stripe choice assay was quantified in bipolar cells with one process located on the Reelin stripe and a second process on the control stripe. Only isolated neurons without contact to other neurons were chosen $(25$ cells from 5 different stripe matrices). Fluorescence images were collected using an Axioskop 2 (Carl Zeiss) and an Axiocam digital camera (Carl Zeiss). For data acquisition, Axiovision software (Carl Zeiss) was used. Fluorescence intensity of process tips with background fluorescence intensity subtracted was measured by using Image J software (National Institutes of Health).

\section{Results}

Serine 3 phosphorylation of $\mathbf{n}$-cofilin is downregulated in reeler mutant mice As a first step in our study of a potential function of Reelin signaling in n-cofilin phosphorylation, we compared the levels of phosphorylated n-cofilin protein in embryonic cortices (E18) of wild-type animals, heterozygous mice, and reeler mutants. In cortical lysates prepared from reeler mutants, the level of $n$-cofilin serine 3 phosphorylation was found to be significantly lower than that of wild-type animals or heterozygous mice (Fig. 1A,B). No difference was detected when lysates from heterozygous mice and from wildtype animals were compared.

\section{Reelin-induced phosphorylation of $\mathbf{n}$ - cofilin and LIMK1}

To examine whether recombinant Reelin stimulates $n$-cofilin serine 3 phosphorylation in cortical tissue of reeler mutants in vitro, we treated tissue of E17.5 cerebral cortex with recombinant Reelin. Western blot analysis showed that Reelin significantly increased the level of phosphorylated n-cofilin (Fig. $1 C, D)$. Phosphorylation of LIMK1, the $\mathrm{n}$-cofilin-phosphorylating kinase, is similarly increased after Reelin treatment (Fig. $1 C, E)$. Phosphorylation levels of both $\mathrm{n}$-cofilin and LIMK1 were significantly decreased when incubated in the presence of PP2 (4-amino-5-(4-chlorophenyl)-7-(tbutyl) pyrazolo ([3,4-d]) pyrimidine), an inhibitor of Src family kinases (SFKs) (Fig. 1CE). Likewise, the phosphorylation of Src family kinases was increased after incubation with recombinant Reelin and was decreased in the presence of PP2 (Fig. 1C).

\section{Reelin-induced n-cofilin serine 3 phosphorylation is mediated by Dab1, SFKs and PI3K}

The nonreceptor tyrosine kinases Src and Fyn are known to phosphorylate Dab1, an adapter protein associated with the intracellular domains of the Reelin receptors ApoER2 and VLDLR (Howell et al., 1997; Arnaud et al., 2003a; Bock and Herz, 2003). As shown, incubation of reeler cortical tissue in the presence of recombinant Reelin strongly induced phosphorylation of SFKs 
(Fig. 1C). For the next step, we examined whether Reelin-induced serine3 phosphorylation of cofilin is Dab1-dependent. We found that Reelin upregulated phospho-serine 3 -cofilin in $d a b 1^{+/+}$mice and $d a b 1^{+/-}$mice compared with untreated control tissue, although this upregulation was less pronounced than in reeler tissue (Figs. $1 C, D ; 2 A, B$ ). The effect was abolished in $d a b 1^{-1-}$ mutants (Fig. $2 A, B)$. These results suggest that the Reelin-induced serine3 phosphorylation of $n$-cofilin requires the adapter protein Dab1, and confirm that Dab1 phosphorylation is mediated by SFKs, consistent with the observation that absence of $f y n$ and $s r c$ results in a reeler-like phenotype (Kuo et al., 2005). Our results point to an involvement of SFKs in cofilin phosphorylation, because treatment of reeler cortical tissue with Reelin in the presence of the SFK inhibitor PP2 significantly reduced serine3 phosphorylation of cofilin when compared with Reelin treatment alone (Fig. 1C).

Phosphatidylinositol-3-kinase (PI3K) has been shown to interact with the adapter protein Dab1 in response to Reelin signaling and is required for normal cortical lamination (Bock et al., 2003). By using LY294002 and Wortmannin, inhibitors of PI3K, we found that blocking PI3K strongly reduced the Reelin-induced serine 3 phosphorylation of $n$-cofilin; in the presence of the inhibitors, no significant changes were observed between Reelintreated and untreated tissue (Fig. 2C,D). These results suggest that PI3K is involved in Reelin-cofilin signaling.

\section{ApoER2 is required for Reelin-induced serine3}

\section{phosphorylation of $\mathbf{n}$-cofilin}

To investigate whether Reelin-induced serine3 phosphorylation of $\mathrm{n}$-cofilin involves the Reelin receptors ApoER2 and VLDLR, we treated acutely dissociated cerebral cortex from E19 apoer $2^{-/-}$mutants, $v$ ldlr ${ }^{-/-}$mutants, and wild-type mice with recombinant Reelin. Western blot analysis showed that there was no statistically significant difference in the level of $n$-cofilin serine 3 phosphorylation when wild-type tissue and VLDLR ${ }^{-1-}$ tissue were compared. However, n-cofilin serine3 phosphorylation was significantly decreased in tissue of apoer $2^{-/-}$mutants treated with recombinant Reelin (Fig. $2 E, F$ ). Moreover, we also compared the levels of uninduced p-cofilin (not induced by incubation in the presence of Reelin) in E17.5 wild-type tissue with those of E17.5 reeler mice, dab1 $1^{-/-}$mice, and apoer $2^{-/-}$and

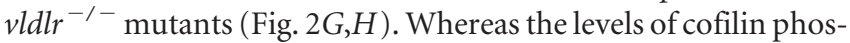
phorylation were significantly decreased in tissue from reeler mice, dab1 $1^{-/-}$mice, and apoer $2^{-/-}$mice, no significant difference from wild-type was found in tissue from $v l d l r^{-/-}$mutants. There were no significant differences in the levels of uninduced p-cofilin between $d a b 1^{-1-}$ mice, apoer $2^{-/-}$mice, and reeler mutants (Fig. $2 H$ ). Together, these findings support our previous observation that ApoER2, but not VLDLR, is required for the proper migration of late-generated neurons that are destined to the superficial layers. In apoer $2^{-1-}$ mutants, but not in $v l d l r^{-/-}$ mutants, late generated neurons are unable to migrate away from their site of generation in the subventricular zone (Hack et al., 2007). We hypothesize that the lack of ApoER2-mediated Reelin signaling leading to decreased serine3 phosphorylation of $\mathrm{n}$-cofilin is involved in this migrational defect.

\section{Phosphorylated n-cofilin is localized to the marginal zone}

Our results have provided evidence for an involvement of the Reelin signaling cascade in serine 3 phosphorylation of $n$-cofilin. During development, Reelin is mainly localized to the marginal zone of the cortex, but some immunoreactivity for Reelin is also seen in deep cortical layers containing early generated neurons (Soriano and Del Rio, 2005) (Fig. 3A). Where would we find phosphorylated n-cofilin? To address this issue, we immunostained sections of E17.5 wild-type and reeler cerebral cortex for Reelin and phosphorylated n-cofilin. We found phosphorylated $\mathrm{n}$-cofilin preferentially located in the Reelin-containing marginal zone and in the cell bodies of early generated deep-layered neurons that extend their apical processes toward the pial surface (Fig. 3A-C). In sections of reeler mutants, staining for Reelin was limited to unspecific labeling of blood vessels (Fig. 3D), with an absence of specific staining in the marginal zone. Immunostaining for serine 3 phospho-cofilin was generally decreased in the reeler cortex with some diffuse staining near the cortical surface (Fig. 3E). The intense staining of deep cortical layers for phospho-cofilin is absent (compare Fig. $3 B, C$ and $E, F$ ), reflecting the migration defect of early generated neurons. The staining for serine 3 phospho-cofilin in the marginal zone of reeler mutants suggests that cofilin may be phosphorylated by other signaling molecules in addition to Reelin. For example, integrin recep- 


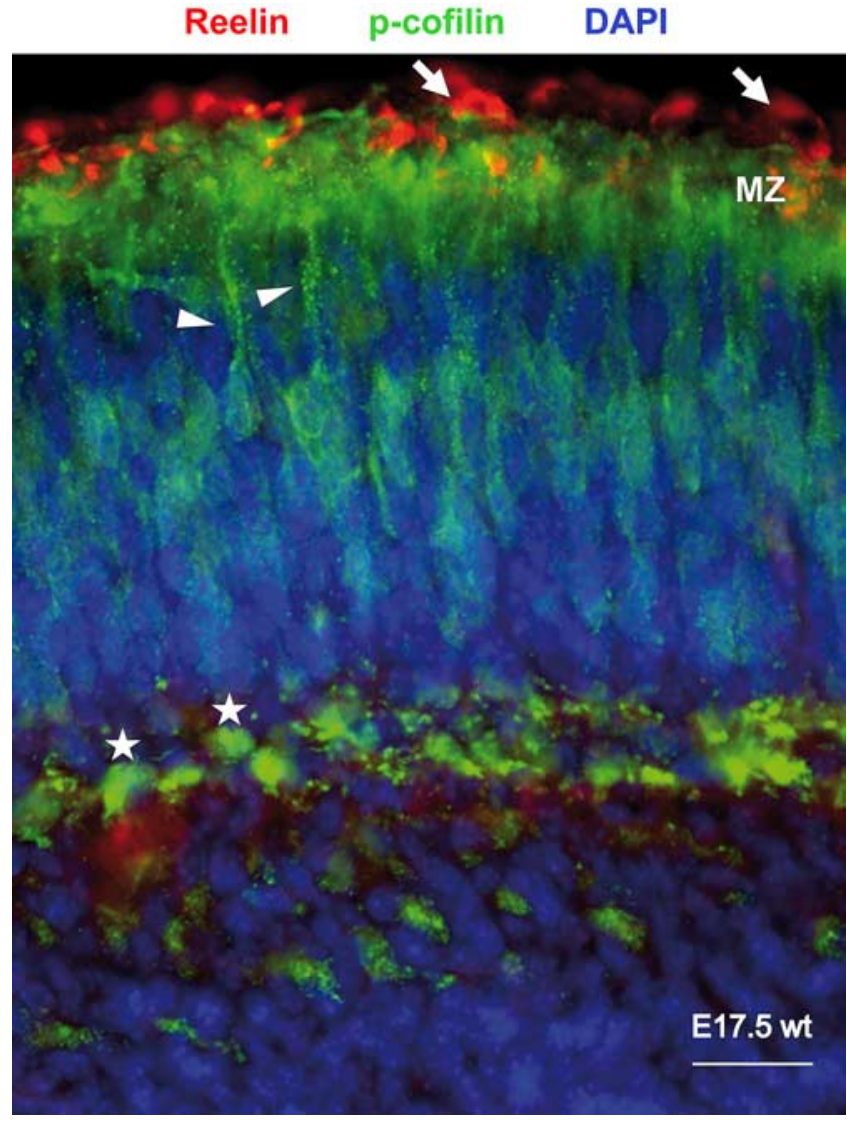

Figure 4. Immunostaining for phosphorylated n-cofilin labels the leading processes of late generated neurons in superficial cortical layers and the cell bodies of early generated neurons of deep layers. Double labeling for Reelin (red) and p-cofilin (green) in a cortical section from an E17.5 wild-type mouse, counterstained with DAPI (blue). Arrowheads point to immunolabeling for $p$-cofilin in the leading processes of neurons located underneath the marginal zone (MZ). Reelin-synthesizing CR cells (red, arrows) were not labeled for p-cofilin. Asterisks label p-cofilinimmunoreactive deep layer neurons. Scale bar, $40 \mu \mathrm{m}$.

tors may interact with the extracellular matrix and can induce the serine3 phosphorylation of $\mathrm{n}$-cofilin via c-Src (Kim et al., 2008).

\section{Phosphorylated $\mathbf{n}$-cofilin is present in the leading processes of radially migrating cortical neurons}

High-power magnification of sections double-labeled for Reelin and phospho-cofilin revealed immunoreactivity for phosphocofilin in the leading processes of neurons located underneath the marginal zone and in the cell bodies of deep-layered neurons (Fig. 4). The figure also demonstrates that phospho-cofilin, although enriched in the marginal zone, is either rarely contained or absent in Reelin-synthesizing Cajal-Retzius cells, a finding that was confirmed when single confocal scans were studied (Fig. 5B). In contrast, double staining for p-cofilin and Map2, a microtubule-associated protein and marker of neuronal dendrites, showed colocalization mainly in dendritic segments approaching the marginal zone (Fig. 5A). Virtually no colocalization was found when antibodies to $\mathrm{p}$-cofilin were combined with the radial glial cell markers Nestin or RC2 (Fig. 5C,D).

\section{Reelin increases n-cofilin phosphorylation in cultured hippocampal neurons}

To visualize Reelin-induced n-cofilin phosphorylation in neurons, primary neuronal cultures prepared from P0 reeler hippocampi were treated with recombinant Reelin or control super- natant. After staining for phalloidin, a marker of F-actin, we noticed that F-actin was localized to neuronal cell bodies and processes (Fig. 6A,D). Immunostaining for phosphorylated $\mathrm{n}$-cofilin labeled the same neuronal processes (Fig. $6 B, C, E, F$ ) but was significantly stronger after treatment with Reelin than with control supernatant of GFP-expressing cells (two-tailed Student's $t$ test, $p<0.01$ ). Double labeling of Reelin-stimulated cells with Map2, a microtubule-associated protein and a marker of neuronal dendrites, revealed similar results to that of phalloidin staining. Incubation in the presence of Reelin increased phosphoserine 3 cofilin immunostaining in Map2-positive cell bodies and dendrites (Fig. 7A-C) when compared with control cells (Fig. $7 D-F)$. Quantification of fluorescence intensity for phosphorylated cofilin revealed significantly higher values for Reelintreated cells when compared with control cells (two-tailed Student's $t$ test, $p<0.01$ ).

Together, our immunocytochemical results of tissue sections and cultured neurons show that Reelin-induced phosphorylation of cofilin at serine 3 takes place in neuronal dendrites. Strong labeling in the marginal zone containing the apical tuft of radially migrating pyramidal neurons suggests that Reelin-induced $\mathrm{n}$-cofilin serine3 phosphorylation might stabilize their leading processes that become the neurons' apical dendrites, anchoring the cells to the surface of the cortex (Pinto-Lord and Caviness, 1979; Miyata et al., 2001).

\section{Stability of neuronal processes is increased on a Reelin substrate}

To study process stability of hippocampal neurons in vitro when encountering a Reelin substrate that imitates the Reelin-rich marginal zone, dissociated hippocampal neurons were incubated on coverslips coated with stripes ( $40 \mu \mathrm{m}$ width) of recombinant Reelin, alternating with control stripes. The differentiation of neuronal processes on the striped substrate was studied within the first $24 \mathrm{~h}$ after plating. Outgrowing neuronal processes did not show a preference for a specific substrate. Thus, many cells immunoreactive for TUJ1, a neuronal marker, were found to give rise to processes on either the control substrate or the Reelin substrate (Fig. $8 \mathrm{~A}$ ). However, an asymmetric distribution of lamellipodia was observed with the lamellipodia-rich processes attached to the control substrate and smooth, lamellipodia-poor processes attached to the Reelin-coated stripe, an effect that was even visible in individual neurons extending different processes to these different substrates (Fig. 8A). In 19 of 25 neurons projecting a process to either stripe, lamellipodia formation was clearly observed in processes on the control stripes but strongly reduced in processes on Reelin stripes. In these studies lamellipodia were defined as flat expansions at the ends of neuronal processes that give rise to microspikes made of actin ribs compared with smooth, spike-free swellings (supplemental Fig. S1 $A, B$, available at www.jneurosci.org as supplemental material). Our findings suggest a Reelin-induced inhibition of lamellipodia formation, likely because of increased phosphorylation of $n$-cofilin at serine3. In fact, when these neurons were immunostained for phosphorylated cofilin, the processes on the Reelin stripes were more heavily labeled than those on the control stripes (Fig. $8 \mathrm{~B}$ ). The mean fluorescence intensity for p-cofilin in terminal swellings was significantly increased on Reelin-coated stripes when compared with control stripes $(p<0.001)$. In line with these results, real-time microscopy of outgrowing processes from neurons located at the border between a Reelin stripe and a control stripe showed a differential process outgrowth depending on the substrate. In time-lapse studies of 4 neurons, each extending dif- 
ferent processes to a Reelin-coated stripe and a control stripe, the processes on the Reelin substrate were stable whereas those on the control substrate were actively growing (Fig. 9). Remarkably, the process labeled by arrow in Figure 9 grew during an initial phase on the Reelin substrate with very low speed but extended quickly on entering the control substrate. Together, these findings indicate cytoskeletal stabilization of neuronal processes encountering Reelin.

\section{Discussion}

The results of the present study show that Reelin signaling induces the phosphorylation of $n$-cofilin. Phosphorylation of $\mathrm{n}$-cofilin at serine 3 was reduced in tissue of Reelin-deficient reeler mutants, and incubation of reeler tissue in the presence of recombinant Reelin strongly increased $\mathrm{n}$-cofilin phosphorylation. In addition, our findings indicate that LIMK1, a kinase that phosphorylates cofilin, is phosphorylated in the presence of Reelin. Phosphorylation of cofilin is strongly reduced in mutants lacking the Reelin receptor ApoER2 or the adaptor protein Dab1. Because phosphorylation of n-cofilin reduces actin dynamics (Moriyama et al., 1996; Nagaoka et al., 1996; Zebda et al., 2000; Jovceva et al., 2007), stabilization of the actin cytoskeleton is likely to play an important role in Reelin's effects on migrating neurons. Acting as a positional signal in the marginal zone (Zhao et al., 2004; Förster et al., 2006a,b), Reelin induces phosphorylation of $n$-cofilin in the leading processes of migrating neurons which may be crucial for the cytoskeletal stabilization that anchors these processes to the marginal zone and is required for the directional migration process (Cooper, 2008).

Reelin signaling is involved in dynamic changes of the actin cytoskeleton Cortical neurons are born in the subventricular zone and migrate to their destinations in the cortical plate by two different modes, somal translocation and gliaguided migration, respectively (Nadarajah and Parnavelas, 2002; Nadarajah et al., 2003; Kubo and Nakajima, 2003; Hatanaka et al., 2004). Somal translocation predominates during the early phases of cortical development; thereafter, when the migratory route to the cortical plate has increased, migrating neurons are guided by radial glial fibers extending from the subventricular zone to the surface of the cortex. Somal translocation is not simply replaced by glia-guided migration during cortical development: After the migration

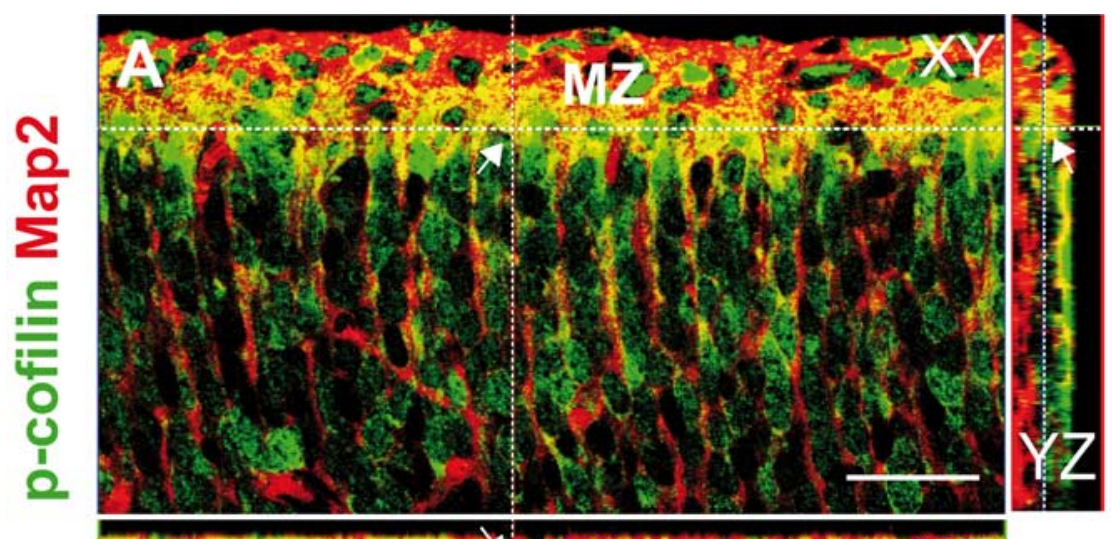

3.4.
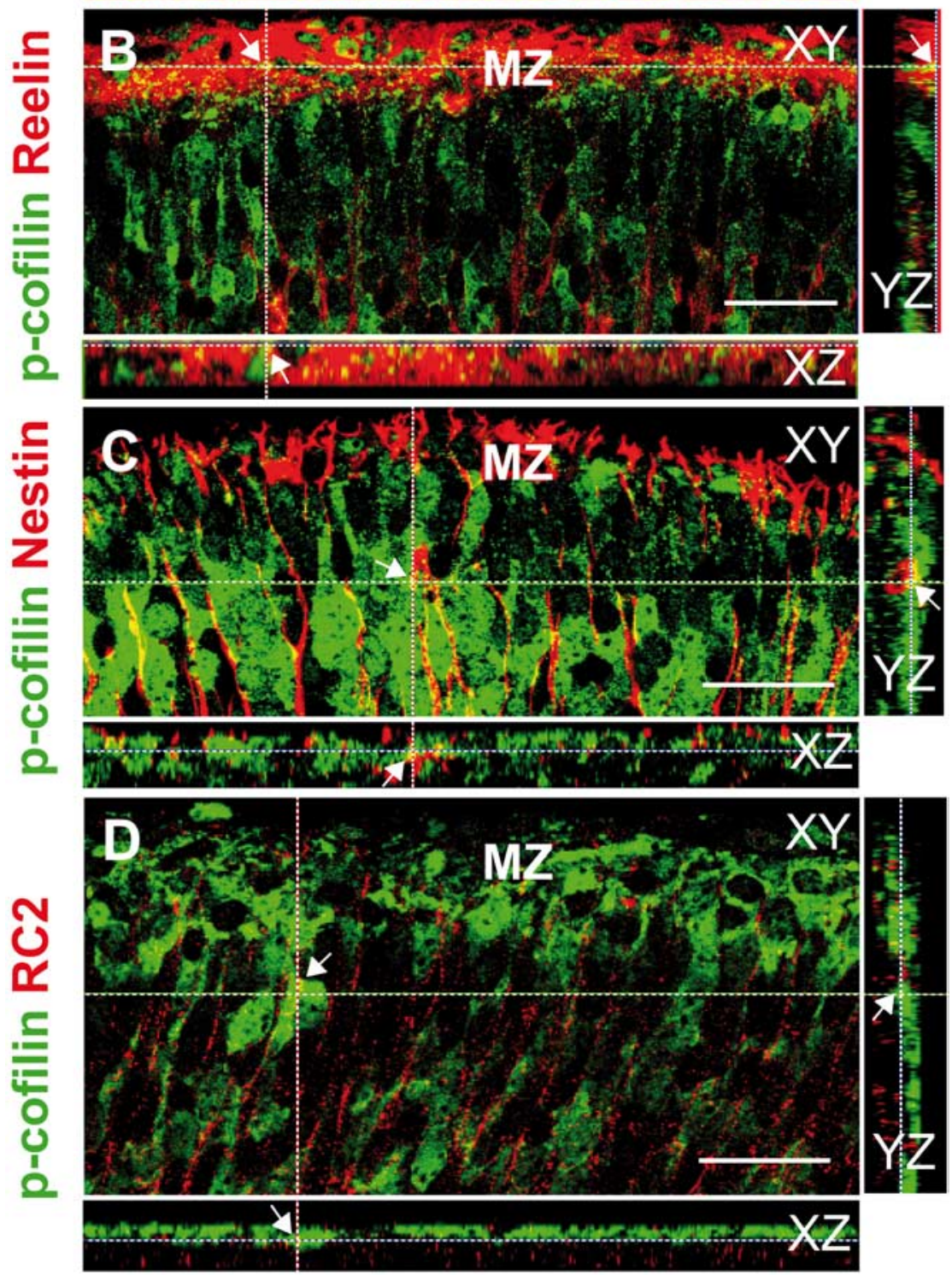

Figure 5. Phosphorylated n-cofilin is localized to Map2-positive neuronal processes but not to Reelin-immunoreactive CR cells and Nestin-positive or RC2-positive radial glial fibers from E17.5 wild-type animals. Single confocal scans from z-series are shown with orthogonal views taken at the levels indicated by white dashed lines. Arrows label structures identifiable in the $X, Y$, and $Z$ planes. $\boldsymbol{A}$, Single confocal section double-immunostained for $p$-cofilin and Map2. Apical neuronal processes close to the marginal zone are colabeled. $\boldsymbol{B}$, Single confocal section double-stained for p-cofilin and Reelin shows minimal colocalization. $\boldsymbol{C}, \boldsymbol{D}$, Virtually no colocalization of $\mathrm{p}$-cofilin and the radial glial markers Nestin and $\mathrm{RC} 2$, respectively, is seen in single confocal sections. The yellow staining of some Nestin-positive processes is likely the result of intimate contact with strongly p-cofilin-positive neurons (white arrows). Scale bars, $50 \mu \mathrm{m}$. 


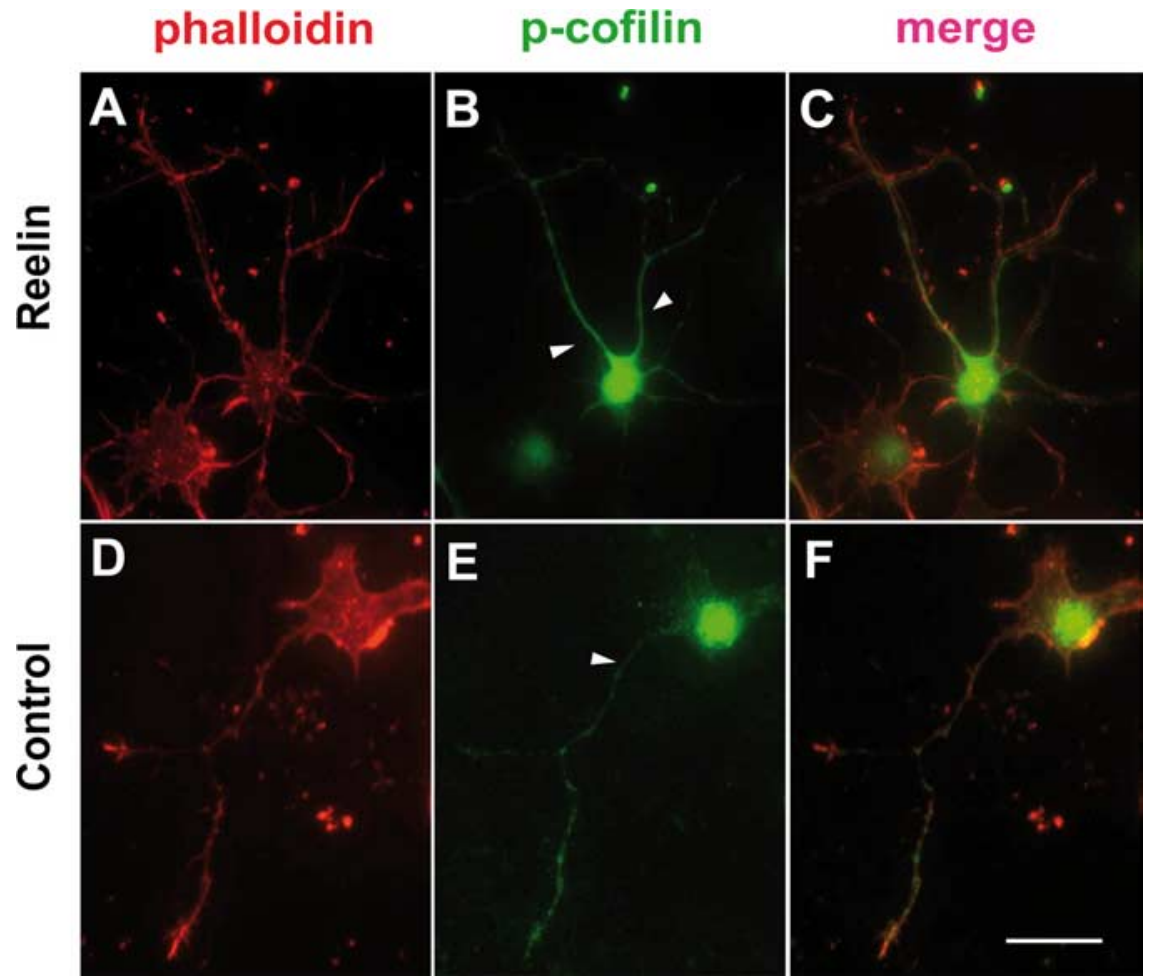

Figure 6. Phosphorylated $n$-cofilin is localized to phalloidin-positive processes of cultured neurons prepared from $P 0$ reeler hippocampus. $\boldsymbol{A}, \boldsymbol{D}$, Immunostaining for phalloidin, a marker of F-actin (red), shows that F-actin is localized to cell bodies and processes. $\boldsymbol{B}, \boldsymbol{C}$, Phosphorylated n-cofilin (green) is clearly present in the same neuronal cell bodies and processes (arrowheads) after incubation in the presence of recombinant Reelin. $\boldsymbol{E}, \boldsymbol{F}$, Immunostaining for phosphorylated $n$-cofilin is weaker in processes (arrowhead) of neurons treated with control supernatant. Scale bar, $(\boldsymbol{A}-\boldsymbol{F}) 15 \mu \mathrm{m}$.

\section{Map2}
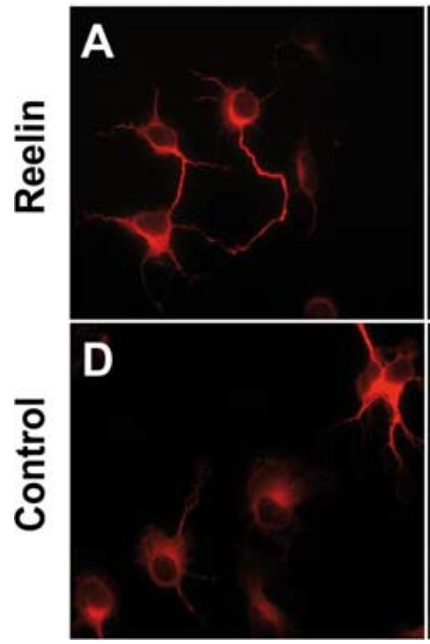

p-cofilin
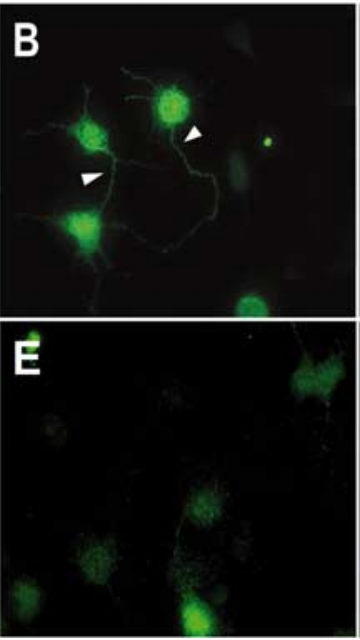

merge
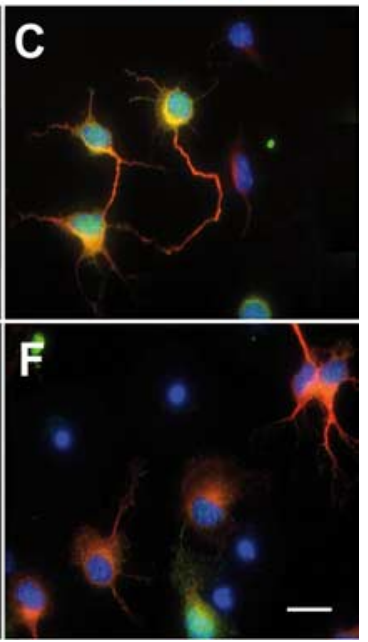

Figure 7. Map2, a microtubule-associated protein and a marker of neuronal dendrites, and p-cofilin overlap in cultured hippocampal neurons from reeler mutants ( $\mathrm{PO}$ ) incubated in the presence of recombinant Reelin. $\boldsymbol{A}$, Staining for Map2 labels neuronal dendrites. $\boldsymbol{B}$, Staining of the same neurons for $\mathbf{p}$-cofilin. Arrowheads point to immunoreactive dendrites. $\boldsymbol{C}$, In an overlay, both Map2 and p-cofilin are contained in the cytoplasm of the same dendrites. $\boldsymbol{D}-\boldsymbol{F}$, Weak immunostaining for $\mathbf{p}$-cofilin in the cell bodies and dendrites of Map2-positive neurons incubated in control supernatant. In $\boldsymbol{C}$ and $\boldsymbol{F}$, cells are counterstained with DAPI (blue). Scale bar, $(\boldsymbol{A}-\boldsymbol{F}) 15 \mu \mathrm{m}$.

along radial glial fibers, late generated neurons eventually move toward their final destination by somal translocation (Nadarajah et al., 2001; Cooper, 2008).

How is Reelin signaling involved in these processes? Suetsugu et al. (2004) have suggested that Dab1 activates N-WASP (neu- ronal Wiskott-Aldrich syndrome protein) and induces actin polymerization through the Arp2/3 (actin-related protein 2/3) complex. The Arp2/3 complex is known to initiate new actin polymerization at the leading edge of migrating cells. Overexpression of Dab1 in COS-7 cells induced filopodia formation, a process associated with increased cell motility. In contrast, Dab1 phosphorylation by Fyn reduced filopodia formation (Suetsugu et al., 2004). Binding of Reelin to ApoER2 and VLDLR, respectively, results in the phosphorylation of Dab1 by Fyn and Src kinases and the ubiquitination of phosphorylated Dab1 as a mechanism of protein degradation (Arnaud et al., 2003b; Bock et al., 2004). These findings indicate a means by which Reelin signaling via phosporylation and ubiquitination of Dab1 controls Dab1 levels and, in turn, actin cytoskeleton dynamics (Winder, 2004).

Cooper and his associates (Feng et al., 2007) have recently extended these studies and have shown that degradation of Dab1 depends both on Dab1 phosphorylation at specific tyrosine residues and the $\mathrm{E} 3 \mathrm{ubiq}-$ uitin ligase component Cullin5 (Cul5). Ablation of Cul5 in migrating neurons prevented Dab1 degradation. Accumulation of Dab1 protein resulted in an excess of migrating neurons at the top of the cortical plate ("overmigration"). Reelin signaling, which induces Dab1 phosphorylation and ubiquitination, thus counteracts the promigratory role of Dabl (Feng et al., 2007; Kerjan and Gleeson, 2007).

The results of the present study point to an alternative way in which Reelin acts to control actin dynamics. Reelin signaling via ApoER2 and Dab1 phosphorylates LIM kinase 1, the same kinase that phosphorylates n-cofilin at serine3. Cofilin is known to promote lamellipodia formation by generating an abundant supply of actin monomers (Kiuchi et al., 2007). Lamellipodia are formed at the leading processes of migrating neurons. Phosphorylation at serine3 renders $\mathrm{n}$-cofilin unable to depolymerize actin filaments, a process which is otherwise necessary to stabilize the actin cytoskeleton (Moriyama et al., 1996; Nagaoka et al., 1996; Zebda et al., 2000; Jovceva et al., 2007). Remarkably, Reelin-induced ubiquitination of Dab1 and n-cofilin phosphorylation reduce formation of filopodia and lamellipodia, respectively, thus decreasing cell motility rather than stimulating it. However, it is the reeler phenotype that is characterized by the inability of lategenerated neurons to bypass their predecessors, resulting in an inversion of cortical layers. Reelin signaling via ApoER2 was recently found to be important for late generated neurons to migrate to superficial positions (Hack et al., 2007). How does Reelin-induced 
phosphorylation of n-cofilin, which is mediated via ApoER2, and the resulting stabilization of the cytoskeleton, contribute to the directional migration of late-generated neurons to superficial layers in the cortex?

\section{Reelin is a positional signal in the marginal zone}

Recent studies have shown that radial glial cells express molecules of the Reelin signaling cascade (Förster et al., 2002; Luque et al., 2003), adhere to a Reelin-, but not control substrate (Förster et al., 2002; Frotscher et al., 2003), and extend their processes toward a Reelin source (Förster et al., 2002; Hartfuss et al., 2003; Zhao et al., 2004). Because radial glial cells are precursors of neurons (Malatesta et al., 2000; Noctor et al., 2001; Götz et al., 2002; Kriegstein and Götz, 2003) and the radial glial fiber is inherited by one of the daughter cells and becomes the neuron's leading process and apical dendrite, respectively (Miyata et al., 2001), the polar orientation of these processes is also likely to depend on the presence of Reelin in the marginal zone. In fact, in reeler mutants, many misoriented pyramidal cells are found (Landrieu and Goffinet, 1981; Terashima et al., 1985, 1992). The tips of both radial glial fibers and apical dendrites are known to branch in the marginal zone, thereby anchoring the parent cells to the pial surface, a process that may be crucial for the directional movement of radially migrating neurons (Olson et al., 2006).

Unexpectedly, we did not find evidence for increased phosphorylation of cofilin in the endfeet of radial glial fibers in the marginal zone. This was in stark contrast to the increasing $\mathrm{p}$-cofilin immunostaining in the leading processes of neurons approaching the marginal zone. We conclude that neuronal migration by nuclear translocation, which requires cytoskeletal stabilization of the leading process and its anchorage to the pial surface to allow for the directional movement of the nucleus, is impaired in the absence of Reelininduced cofilin phosphorylation. This view is supported by a relatively normal radial glial scaffold in the neocortex (but not hippocampus) (Weiss et al., 2003) of reeler mice and ApoER2 mutants (Hack et al., 2007).

\section{Reelin signaling stabilizes the cytoskeleton by n-cofilin phosphorylation}

As one would expect, immunostaining for phospho-cofilin is very strong in the marginal zone containing CR cells which synthesize and secrete Reelin. Migrating neurons extend their leading processes toward the marginal zone, and phospho-cofilin immunostaining was seen in these processes (Fig. 4). We conclude that the Reelin-induced phosphorylation of $\mathrm{n}$-cofilin takes place in these processes, thereby attaching them to the marginal zone
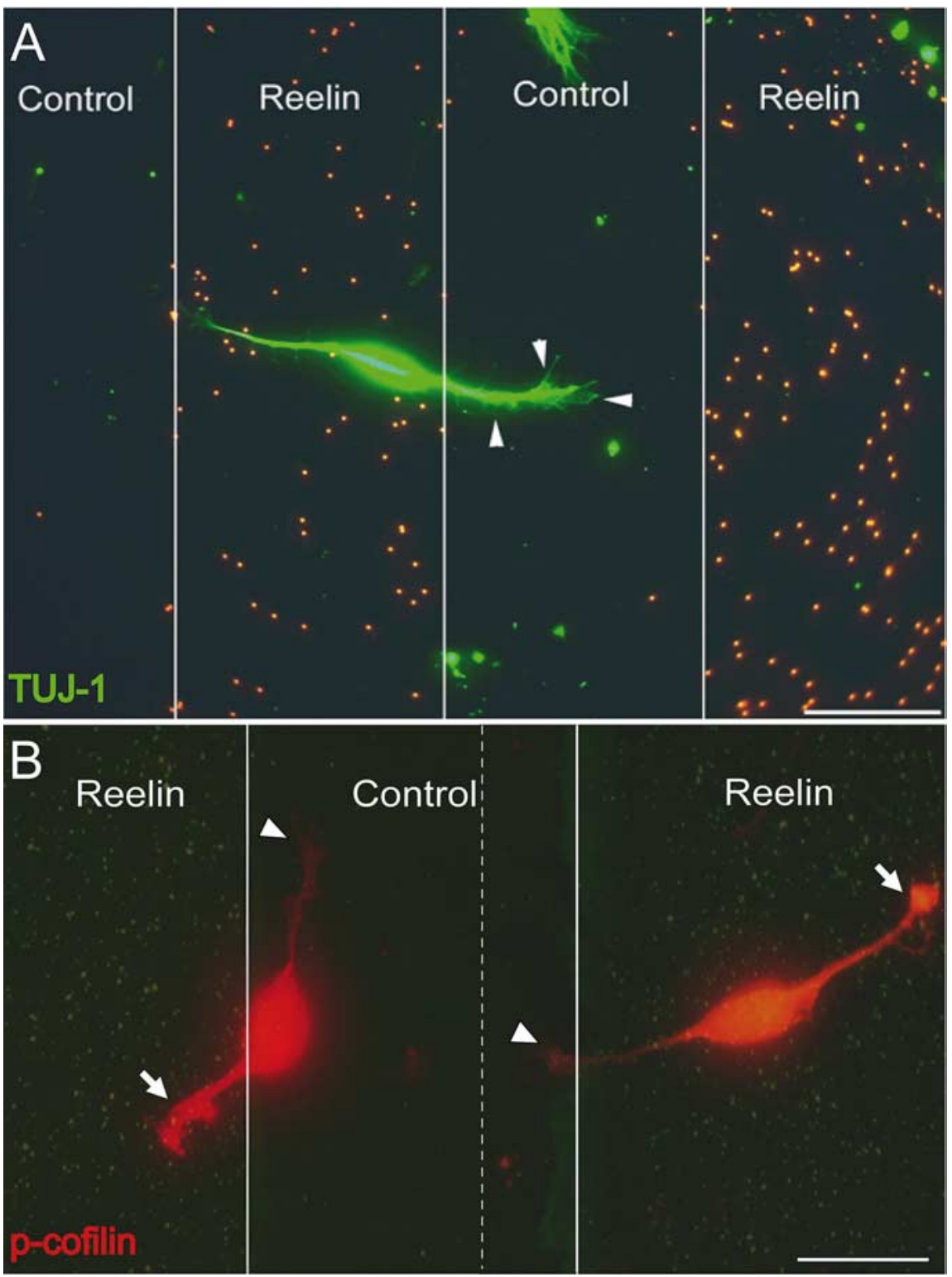

Figure 8. Reelin stabilizes neuronal processes by phosphorylation of n-cofilin at serine3. $A$, TUJ-1-positive neuron partially located on a Reelin stripe (identified by red fluorescent beads) and on a control stripe. While the process on the Reelin stripe shows smooth contours, a lamellipodium with several microspikes is visible in the process on the control stripe (arrowheads). Scale bar, antibodies) and control stripes. The processes on the Reelin stripes are heavily immunoreactive for p-cofilin (arrows), whereas those on the control stripes (arrowheads) are only weakly stained. The dotted line is to indicate that the two cells are from two different preparations. Scale bar, $15 \mu \mathrm{m}$.

and providing the proper orientation for the directional migration process. In turn, decreased levels of phosphorylated n-cofilin in the absence of Reelin are likely to be accompanied by a persistent dynamic reorganization of the cytoskeleton, and thus a relative instability of these processes, resulting in an altered orientation and migration of neurons in the reeler mutant. Using the stripe choice assay, even different processes of individual neurons were found to display a different behavior: Processes extending to Reelin stripes were stable over time, whereas those on control stripes developed lamellipodia as a sign of ongoing actin dynamics, and increased considerably in length over a time period of an hour (Fig. 9). Remarkably, in a recent study analyzing proteome changes induced by RNA interference-mediated alterations in actin signaling, phospho-cofilin was the only protein identified 

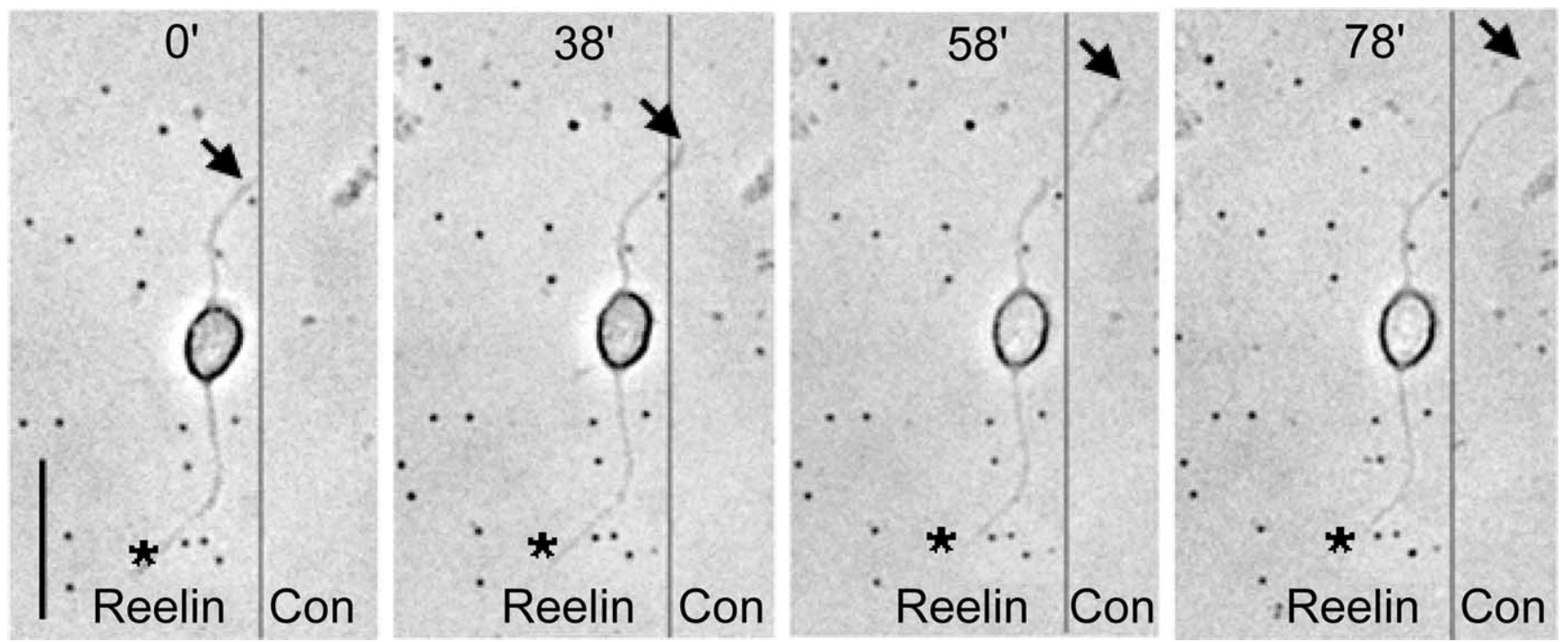

Figure 9. Time-lapse study of a neuron with processes extending to a Reelin stripe and a control stripe. Whereas the process on the Reelin stripe (asterisk) did not change over time (78 min), the process extending to the control stripe (arrow) increased considerably in length during this period. Scale bar, $20 \mu \mathrm{m}$.

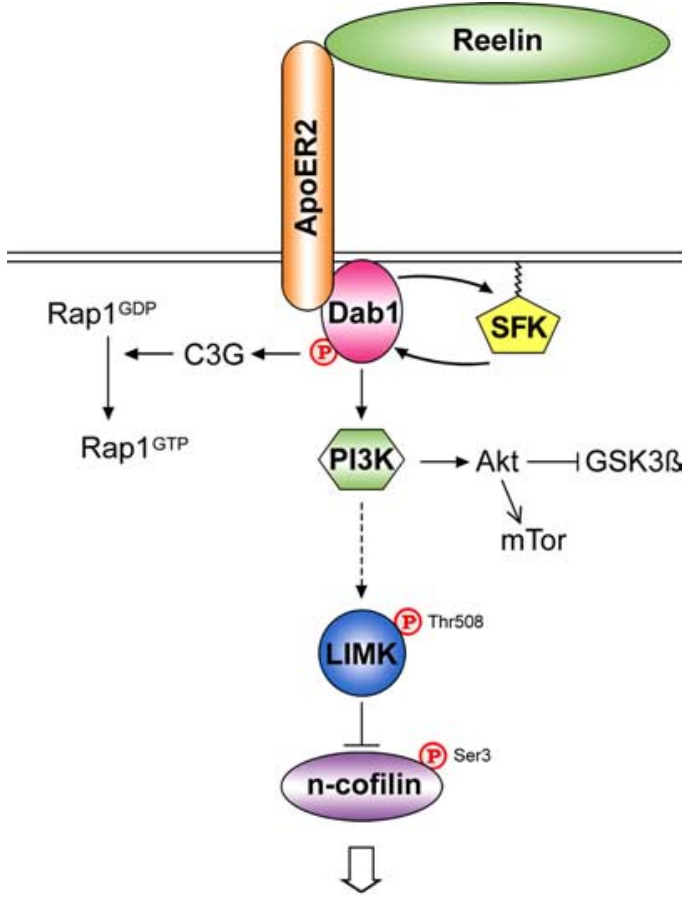

F-actin stabilization

Figure 10. Schematic diagram of LIM kinase-dependent inhibition of n-cofilin activity by Reelin. Binding of Reelin to the transmembrane receptor ApoER2 induces reciprocal activation (arrows) of the receptor-associated cytosolic adapter protein Disabled-1 (Dab1) and neuronal Src family kinases (SFKs). This leads to the activation of phosphatidylinositol 3-kinase (PI3K), which is required for the phosphorylation of LIM kinase1 (LIMK) at threonine 508 through unknown upstream regulators (dotted arrow). The subsequent phosphorylation at serine 3 renders $\mathrm{n}$-cofilin unable to depolymerize $\mathrm{F}$-actin, thereby contributing to stabilization of the actin cytoskeleton in the leading processes of migrating neurons in the developing cortical plate (Fig. 4). This pathway is primarily mediated by ApoER2, whose genetic ablation blocks Reelindependent phosphorylation of cofilin, whereas the second Reelin lipoprotein receptor, VLDLR, seems to be dispensable (Fig. 2E, F). Other Reelin-induced signaling cascades that potentially modulate the actin cytoskeleton and microtubule stability include the activation of the small GTPase Rap 1 and the inhibition of the Tau kinase glycogen synthase kinase-3 $\beta$ (GSK3 $\beta$ ), which involves the PI3K-dependent activation of the protein kinase Akt (Beffert et al., 2002; Ballif et al., 2004; Jossin and Goffinet, 2007). C3G, Crk SH3-binding guanine nucleotide-releasing protein; mTor, mammalian target of rapamycin. whose expression correlated with actin filament levels and lamellipodia formation (Jovceva et al., 2007). During the actual migration process cytoskeletal stabilization and lamellipodia formation in the leading process may fluctuate depending on the availability of phosphorylated Dab1: Phosphorylation of n-cofilin may be terminated by the ubiquitination of phosphorylated Dab1 (Feng et al., 2007).

The present study provides evidence for the involvement of signaling molecules of the Reelin pathway such as Dab1, SFKs, and PI3K in LIMK1 and cofilin phosphorylation (Fig. 10). Regarding the role of Reelin receptors in the phosphorylation of n-cofilin, ApoER2 appears to be required to a greater extent than VLDLR. Previous studies have shown that in apoer 2 mutants, but not vldlr mutants, late-generated cortical neurons are unable to bypass earlier-generated cells and remain near their site of generation (Hack et al., 2007). We hypothesize that directional migration is altered in these late-generated neurons, likely because of an altered cytoskeletal stabilization of their leading processes.

In conclusion, the results of the present study suggest that cytoskeletal stabilization by $\mathrm{n}$-cofilin phosphorylation may be a novel mechanism by which Reelin controls actin dynamics and the orientation of migrating neurons.

\section{References}

Angevine JB, Sidman RL (1961) Autoradiographic study of cell migration during histogenesis of cerebral cortex in the mouse. Nature 192:766-768. Arber S, Barbayannis FA, Hanser H, Schneider C, Stanyon CA, Bernard O, Caroni P (1998) Regulation of actin dynamics through phosphorylation of cofilin by LIM-kinase. Nature 393:805-809.

Arnaud L, Ballif BA, Förster E, Cooper JA (2003a) Fyn tyrosine kinase is a critical regulator of Disabled-1 during brain development. Curr Biol 13:9-17.

Arnaud L, Ballif BA, Cooper JA (2003b) Regulation of protein tyrosine kinase signaling by substrate degradation during brain development. Mol Cell Biol 23:9293-9302.

Ballif BA, Arnaud L, Arthur WT, Guris D, Imamoto A, Cooper JA (2004) Activation of a Dab1/CrkL/C3G/Rapl pathway in Reelin-stimulated neurons. Curr Biol 14:606-610.

Bamburg JR (1999) Proteins of the ADF/cofilin family: essential regulators of actin dynamics. Annu Rev Cell Biol 15:185-230.

Beffert U, Morfini G, Bock HH, Reyna H, Brady ST, Herz J (2002) Reelinmediated signaling locally regulates protein kinase B/Akt and glycogen synthase kinase 3beta. J Biol Chem 277:49958-49964. 
Bellenchi GC, Gurniak CB, Perlas E, Middei S, Ammassari-Teule M, Witke W (2007) N-cofilin is associated with neuronal migration disorders and cell cycle control in the cerebral cortex. Genes Dev 21:2347-2357.

Berry M, Rogers AW (1965) The migration of neuroblasts in the developing cerebral cortex. J Anat 99:691-709.

Bock HH, Herz J (2003) Reelin activates SRC family tyrosine kinases in neurons. Curr Biol 13:18-26.

Bock HH, Jossin Y, Liu P, Förster E, May P, Goffinet AM, Herz J (2003) Phosphatidylinositol 3-kinase interacts with the adapter protein Dab1 in response to Reelin signaling and is required for normal cortical lamination. J Biol Chem 278:38772-38779.

Bock HH, Jossin Y, May P, Bergner O, Herz J (2004) Apolipoprotein E receptors are required for Reelin-induced proteasomal degradation of the neuronal adaptor protein disabled-1. J Biol Chem 279:33471-33479.

Cooper JA (2008) A mechanism for inside-out lamination in the neocortex. Trends Neurosci 31:113-119.

Curran T, D'Arcangelo G (1998) Role of reelin in the control of brain development. Brain Res Rev 26:285-294.

D’Arcangelo G, Nakajima K, Miyata T, Ogawa M, Mikoshiba K, Curran T (1997) Reelin is a secreted glycoprotein recognized by the CR-50 monoclonal antibody. J Neurosci 17:23-31.

Dawe HR, Minamide LS, Bamburg JR, Cramer LP (2003) ADF/cofilin controls cell polarity during fibroblast migration. Curr Biol 13:252-257.

Feng L, Allen NS, Simo S, Cooper JA (2007) Cullin 5 regulates Dab1 protein levels and neuron positioning during cortical development. Genes Dev 21:2717-2730.

Förster E, Tielsch A, Saum B, Weiss KH, Johanssen C, Graus-Porta D, Müller U, Frotscher M (2002) Reelin, Disabled 1 and betal integrins are required for the formation of the radial glial scaffold in the hippocampus. Proc Natl Acad Sci U S A 99:13178-13183.

Förster E, Jossin Y, Zhao S, Chai X, Frotscher M, Goffinet AM (2006a) Recent progress in understanding the role of Reelin in radial neuronal migration, with specific emphasis on the dentate gyrus. Eur J Neurosci 23:901-909.

Förster E, Zhao S, Frotscher M (2006b) Laminating the hippocampus. Nat Rev Neurosci 7:259-267.

Frotscher M (1998) Cajal-Retzius cells, Reelin, and the formation of layers. Curr Opin Neurobiol 8:570-575.

Frotscher M, Haas CA, Förster E (2003) Reelin controls granule cell migration in the dentate gyrus by acting on the radial glial scaffold. Cereb Cortex 13:634-640.

Ghosh M, Song X, Mouneimne G, Sidani M, Lawrence DS, Condeelis JS (2004) Cofilin promotes actin polymerization and defines the direction of cell motility. Science 304:743-746.

Götz M, Hartfuss E, Malatesta P (2002) Radial glial cells as neuronal precursors: a new perspective on the correlation of morphology and lineage restriction in the developing cerebral cortex of mice. Brain Res Bull 57:777-788.

Hack I, Hellwig S, Junghans D, Brunne B, Bock HH, Zhao S, Frotscher M (2007) Divergent roles of ApoER2 and VLDLR in the migration of cortical neurons. Development 134:3883-3891.

Hartfuss E, Förster E, Bock HH, Hack MA, Leprince P, Luque JM, Herz J, Frotscher M, Götz M (2003) Reelin signaling directly affects radial glia morphology and biochemical maturation. Development 130:4597-4609.

Hatanaka Y, Hisanaga S, Heizmann CW, Murakami F (2004) Distinct migratory behavior of early- and late-born neurons derived from the cortical ventricular zone. J Comp Neurol 479:1-14.

Hiesberger T, Trommsdorff M, Howell BW, Goffinet A, Mumby MC, Cooper JA, Herz J (1999) Direct binding of Reelin to VLDL receptor and ApoE receptor 2 induces tyrosine phosphorylation of disabled-1 and modulates tau phosphorylation. Neuron 24:481-489.

Howell BW, Hawkes R, Soriano P, Cooper JA (1997) Neuronal position in the developing brain is regulated by mouse disabled-1. Nature 389:733-737.

Howell BW, Herrick TM, Cooper JA (1999) Reelin-induced tyrosine phosphorylation of disabled 1 during neuronal positioning. Genes Dev 13:643-648.

Hunter-Schaedle KE (1997) Radial glial cell development and transformation are disturbed in reeler forebrain. J Neurobiol 33:459-472.

Jossin Y, Goffinet AM (2007) Reelin signals through phosphatidylinositol 3-kinase and Akt to control cortical development and through mTor to regulate dendritic growth. Mol Cell Biol 27:7113-7124.
Jovceva E, Larsen MR, Waterfield MD, Baum B, Timms JF (2007) Dynamic cofilin phosphorylation in the control of lamellipodial actin homeostasis. J Cell Science 120:1888-1897.

Kerjan G, Gleeson JG (2007) A missed exit: Reelin sets in motion Dab1 polyubiquitination to put the break on neuronal migration. Genes Dev 21:2850-2854

Kim YB, Choi S, Choi MC, Oh MA, Lee SA, Cho M, Mizuno K, Kim SH, Lee JW (2008) Cell adhesion-dependent cofilin serine 3 phosphorylation by the integrin-linked kinase c-Src complex. J Biol Chem 283:10089-10096.

Kiuchi T, Ohashi K, Kurita S, Mizuno K (2007) Cofilin promotes stimulusinduced lamellipodium formation by generating an abundant supply of actin monomers. J Cell Biol 177:465-476.

Knöll B, Weinl Ch, Nordheim A, Bonhoeffer F (2007) Stripe assay to examine axonal guidance and cell migration. Nature Prot 2:1216-1221.

Konno D, Yoshimura S, Hori K, Maruoka H, Sobue K (2005) Involvement of $\mathrm{PI} 3 \mathrm{~K} / \mathrm{Racl}$ and $\mathrm{Cdc} 42$ pathways in radial migration of cortical neurons. J Biol Chem 280:5082-5088.

Kriegstein AR, Götz M (2003) Radial glia diversity: a matter of cell fate. Glia 43:37-43.

Kubo K, Nakajima K (2003) Cell and molecular mechanisms that control cortical layer formation in the brain. J Med 52:8-20.

Kuo G, Arnaud L, Kronstad-O’Brien P, Cooper JA (2005) Absence of Fyn and Src causes a reeler-like phenotype. J Neurosci 25:8578-8586.

Lambert de Rouvroit C, Goffinet AM (1998) The reeler mouse as a model of brain development. Adv Anat Embryol Cell Biol 150:1-106.

Landrieu P, Goffinet A (1981) Inverted pyramidal neurons and their axons in the neocortex of reeler mutant mice. Cell Tissue Res 218:293-301.

Luque JM, Morante-Oria J, Fairén A (2003) Localization of ApoER2, VLDLR and Dab1 in radial glia: groundwork for a new model of reelin action during cortical development. Brain Res Dev Brain Res 140:195-203.

Malatesta P, Hartfuss E, Götz M (2000) Isolation of radial glial cells by fluorescent-activated cell sorting reveals a neuronal lineage. Development 127:5253-5263.

Miyata T, Kawaguchi A, Okano H, Ogawa M (2001) Assymetric inheritance of radial glial fibers by cortical neurons. Neuron 31:727-741.

Moriyama K, Iida K, Yahara I (1996) Phosphorylation of Ser-3 of cofilin regulates its essential function on actin. Genes Cells 1:73-86.

Nadarajah B, Parnavelas JG (2002) Modes of neuronal migration in the developing cerebral cortex. Nat Rev Neurosci 3:423-432.

Nadarajah B, Brunstrom JE, Grutzendler J, Wong RO, Pearlman AL (2001) Two modes of radial migration in early development of the cerebral cortex. Nat Neurosci 4:143-150.

Nadarajah B, Alifragis P, Wong RO, Parnavelas JG (2003) Neuronal migration in the developing cerebral cortex: Observations based on real-time imaging. Cereb Cortex 13:607-611.

Nagaoka R, Abe H, Obinata T (1996) Site-directed mutagenesis of the phosphorylation site of cofilin: its role in cofilin-actin interaction and cytoplasmic localization. Cell Motil Cytoskeleton 35:200-209.

Noctor SC, Flint AC, Weissman TA, Dammerman RS, Kriegstein AR (2001) Neurons derived from radial glial cells establish radial units in neocortex. Nature 409:714-720.

Olson EC, Kim S, Walsh CA (2006) Impaired neuronal positioning and dendritogenesis in the neocortex after cell-autonomous Dab1 suppression. J Neurosci 26:1767-1775.

Pinto Lord MC, Caviness VS Jr (1979) Determinants of cell shape and orientation: a comparative Golgi analysis of cell-axon interrelationships in the developing neocortex of normal and reeler mice. J Comp Neurol 187:49-69.

Pollard TD, Borisy GG (2003) Cellular motility driven by assembly and disassembly of actin filaments. Cell 112:453-465.

Rakic P, Caviness VS Jr (1995) Cortical development: view from neurological mutants two decades later. Neuron 14:1101-1104.

Rice DS, Curran T (2001) Role of the reelin signaling pathway in central nervous system development. Annu Rev Neurosci 24:1005-1039.

Sheldon M, Rice DS, D’Arcangelo G, Yoneshima H, Nakajima K, Mikoshiba K, Howell BW, Cooper JA, Goldowitz D, Curran T (1997) Scrambler and yotari disrupt the disabled gene and produce a reeler-like phenotype in mice. Nature 389:730-733.

Soriano E, Del Río JA (2005) The cells of Cajal-Retzius: still a mystery one century after. Neuron 46:389-394.

Suetsugu S, Tezuka T, Morimura T, Hattori M, Mikoshiba K, Yamamoto T, 
Takenawa T (2004) Regulation of actin cytoskeleton by mDab1 through $\mathrm{N}$-WASP and ubiquitination of mDab1. Biochem J 384:1-8.

Terashima T, Inoue K, Inoue Y, Mikoshiba K, Tsukada Y (1985) Distribution and morphology of callosal commissural neurons within the motor cortex of normal and reeler mice. J Comp Neurol 232:83-98.

Terashima T, Takayama C, Ichikawa R, Inoue Y (1992) Dendritic arborization of large pyramidal neurons in the motor cortex of normal and reeler mutant mouse. Okajimas Folia Anat Jpn 68:351-363.

Tissir F, Goffinet AM (2003) Reelin and brain development. Nat Rev Neurosci 4:496-505.

Trommsdorff M, Gotthardt M, Hiesberger T, Shelton J, Stockinger W, Nimpf J, Hammer RE, Richardson JA, Herz J (1999) Reeler/Disabled-like disruption of neuronal migration in knockout mice lacking the VLDL receptor and ApoE receptor 2. Cell 97:689-701.

Ware ML, Fox JW, González JL, Davis NM, Lambert de Rouvroit C, Russo CJ, Chua SC Jr, Goffinet AM, Walsh CA (1997) Aberrant splicing of a mouse disabled homolog, mdab1, in the scrambler mouse. Neuron 19:239-249.

Weiss KH, Johanssen C, Tielsch A, Herz J, Deller T, Frotscher M, Förster E (2003) Malformation of the radial glial scaffold in the dentate gyrus of reeler mice, scrambler mice, and ApoER2/VLDLR-deficient mice. J Comp Neurol 460:56-65.

Winder SJ (2004) Filopodia formation and Disabled degradation downstream of Reelin. Biochem J 384:e1-e2.

Yang N, Higuchi O, Ohashi K, Nagata K, Wada A, Kangawa K, Nishida E, Mizuno K (1998) Cofilin phosphorylation by LIM-kinase 1 and its role in Rac-mediated actin reorganization. Nature 393:809-812.

Zebda N, Bernard O, Bailly M, Welti S, Lawrence D (2000) Phosphorylation of $\mathrm{ADF} /$ cofilin abolishes EGF-induced actin nucleation at the leading edge and subsequent lamellipod extension J Cell Biol 151:1119-1127.

Zhao S, Chai X, Förster E, Frotscher M (2004) Reelin is a positional signal for the lamination of dentate granule cells. Development 131:5117-5125. 